

\title{
LITERATURE
}

LWATI: A Journal of Contemporary Research, 1(1), 168-177, 2010

ISSN: $1813-2227$

UAS

\section{From Pedagogy to Drama Therapy: a Study of Chris Nwamuo's Theatre}

\author{
Chris Egharevba \\ Department of English, University of Uyo, Uyo \\ E-Mail: Uniquekriz@,Yahoo.Com
}

\begin{abstract}
Over the years in Nigeria, Theatre has played a significant role in raising the level of Socio-political consciousness of the masses. During the colonial era theatre practitioners had produce plays that were politically uncomfortable to the colonial regimes. Since the dawn of independence the problem of nation building has consumed the consciousness of theatre practitioners. However, this essay takes the position that the philosophy of contemporary theatre is moving from a pedagogic philosophy, which is a theatre that is conscious of raising the awareness of the masses to a deeper understanding of the individual self and a therapeutic solution to daily existence. Chris Nwamuo's theatre is examined to explore this contemporary concern of Nigerian drama.
\end{abstract}

\section{INTRODUCTION}

I will align my understanding of theatre to its very simplistic definition giving by the playwright under study to wit: theatre is a "demonstration of any action by anyone or a group of people at a particular place and moment in time, with or without make-up, costume, rehearsal or improvisation before an audience gathered by a common interest to share and to celebrate. At times, the joy and celebration may lead to clapping, deep emotional feelings and responses, intellectual stimulation recreation and the appreciation of human artistry in its coordinated form". ( Nwamuo, 2002: 2-3) It is a mirror of society of which it is a part and that it accurately reflects the life of its age" ( Nwamuo 2006)

In his essay "Soyinka and the Philosophy of Nigerian Theatre", Nwamuo examines the philosophies that have directed theatre practice in Nigeria before independence and during the modern time (1960-present). The essay highlights the characteristics shaping and guiding the principles of 


\section{A Study of Chris Nwamuo's Theatre}

Nigerian theatre and proposes guidelines for popular theatre for future practitioners. He observes that the plays of the period before 1960 in Nigeria were interested in the rhetoric, erudition and the refined language of the colonialist as in political and cultural nationalism. Little "attention was paid to the audience; their involvement, understanding, participation and identification with the drama." (Nwamuo, 2002:1)

The history of theatre in Nigeria showed that theatre has played a significant role over the years in raising the level of socio-political consciousness of the mass of the people of the country. The colonial era saw the emergence of several African theatre practitioners who were nurtured in the European tradition. However, as the colonial policies became outrageous the theatre artists began using the theatre as a weapon to react against the excesses of the colonial regimes" (Idoye, 1986: 72).

\section{I}

The focus of most theatrical productions since the dawn of independence has been the problems of nation building. In meeting this challenge of nation building, theatre practitioners evolve a social action theatre. This in effect is a functional theatre which is relevant not only to the people's life style but contributes tremendously to the overall development of the society.

In Ahmadu Bello University, Zaria while a student of drama under Michael Etherton in the 1970s, the drama department was concerned with the theatre that was aimed at raising the awareness of the audience to social problem that affect them. It was a theatre that was directed to the masses so that they will be able to comprehend the various forces of social change that oppress them. This is an example of theatre of liberation.

It is a theatre that is essentially pedagogic for it highlights the problem of the people, creates awareness and demands for action. Most of the dramas that emerge from the socialist perspective belong to this pedagogic theatre. Nwamuo's theatre portrays the response of a creative mind and sensitive conscience to the misery, ignorance and the suffering of the oppressed around him.

His plays present the concrete realities of the world of the masses and this encourages and equipped them to know and respond to their world instead of continuing in what Paulo Freire called "the culture of silence" of the dispossessed. In other words, Nwamuo in his theatre is against this culture of silence and ignorance by those in penury and ignorance. He shows that oppression and poverty dehumanize the individual and thus presents characters that struggle and fight against agents that perpetuate or create such twin situations in our world.

However, I see Nwamuo's theatre as transiting to another level. We see Nwamuo's theatre as a liberating theatre: liberating people from the shackles of ignorance, poverty and disease. Nwamuo's plays present individuals who are "thwarted by injustice, exploitation, oppression and the violence of the 


\section{Chris Egharevba}

oppressors; [his plays] affirm the yearning of the oppressed for freedom and justice by their struggle to recover their lost humanity" (20).

According to Paulo Freire, "to surmount the situation of oppression, men must first critically recognize its causes" (24). This Nwamuo's theatre seeks to achieve: first (to create situations for a critical recognition of the essence of oppression in human life and second surmount the situation of oppression) he seeks to surmount the situation of oppression by making characters to critically recognize the causes of oppression. Thus we see that in his plays, this pedagogy makes oppression and its causes objects of reflection by the oppressed, transforming the oppressed from the 'culture of silence' to a situation where the masses engage in confrontation for their liberation as we see in plays like The Squeeze and The Prisoners.

From such pedagogic drama, Nwamuo's theatre translates to dramatherapy: drama of purgation of the contradictions within the oppressed. Thus the characters will now perceive the reality of oppression, not as a closed world from which there is no exit but as a limiting situation which they can transform. Man will come to this achievement after a therapy that begins from within. Liberating actions necessarily involves a moment of perception (pedagogic) and volition (therapy) and it is this totality that Nwamuo shows to us in his theatre: a theatre that makes us have a full perception of our world and also possess the will to act positively on our world.

However, modern Nigerian theatre presents a philosophy that is directed towards the celebration and sharing of an experience involving the community. It is the philosophy of popular theatre, a theatre which thrives on a "communion of vibrations, a sharing of ideas and emotions, a cumulative force, a celebration of life through the dramatic idioms of mask, song, dance, speech, music, mine, magic, ritual, masquerade, story-telling and ceremony with didactic motive" (Nwamuo, 2006:6), a theatre which celebrates the concern of the ordinary people. Nwamuo's theatre takes off from this platform.

One major critique Nwamuo highlighted in his essay on Wole Soyinka drama, is soyinka's uncertainly about the audience he writes for. "Soyinka has maintained" Nwamuo writes" that he (Soyinka) does not think of any particular audience" when writing, for he claimed that "he writes for every stratum of society, people who feel the same way he does about certain things in the society." This Chris Nwamuo queried for in writing, selecting, directing and producing a play for Nigeria," audience should be considered first" (Nwamuo, 2006:8-9).

This gives us indices about his concern in his plays Nwamuo's theatre is thus a theatre that not only celebrates the concerns of the ordinary people but is aimed at engineering the audience towards a profound participation in his plays.

He advocates a dynamic relationship between the audience and the stage for it is in this relationship that "one must seek the truth of a theatrical phenomenon called popular theatre" (p15) It is this dynamism of audience 


\section{A Study of Chris Nwamuo's Theatre}

engineering which formed the crux of his 32 nd Unical Inaugural Lecture that underscored the concept of seeing Nwamuo's theatre beyond mere pedagogic concern to seeing his theatre in the light of group therapy.

In his inaugural lecture (March, 2006) Nwamuo observes that theatre requires audiences all the time to criticize and imbibe its messages and reform programmes. As theatre audiences are drawn together by the event and the appetite for art, they also converge to commune, share and enjoy the event and develop relationships with other people. The experience of theatre has the potential of significantly changing the lives of audience members. In fact, the administration of audiences who have come to the theatre to engage with new ideas while being entertained is associated with human psychology and audience engineering. (p.7)

This is the domain of dramatherapy or Group therapy.

The theatre audience is drawn together by a number of factors. According to Nwamuo, the audience is drawn together by the social as well as artistic experience. To some members of the audience, theatre" stirs their imagination, reveals the familiar and reveals the exotic. In addition, the audience as it shares in the collective applause, the laughter, the tears, the joy or solemnity of the event presented to it consciously enter into a relationship, by homogenously surrounding into a therapeutic experience as a group, no matter how diversified the constituent of the audience. It is in this group therapy among other theatrical concern, that the engineer of the audience, the therapist of the people that Professor Chris Nwamuo demonstrated his strength in his drama.According to Kachua, the basic tenets of Nwamuo's idea are humanistic. Being of a humble upbringing, he is ill at-ease with the evil that attends the gradation of society into ranks and hierarchical orders. The apparent plight of the underprivileged in the society disturbs him and manifests copiously in his creative works. He is consciously a Marxist writer..." (27).

However, Nwamuo is not a Marxist. His plays and theatre are influenced by Marxist thinking for there is a difference between a Marxist and a writer whose works are influenced by Marxism. Chris Nwamuo is guided by a Christian-New Humanistic philosophy that recognizes the Fatherhood of God and sees man as created in God's image and is thus concerned with the plight of the oppressed and thus sees oppression as evil that needs to be eliminated from our society.

\section{I}

Drama or theatre is essentially a therapeutic art form. And more than other art forms, theatre is a group art. It brings together a group of people who we call casts or performers and another group we call the audience. Together these groups participate in a live performance within a space to experience a therapy that is initiated or directed by the playwright who is the therapist. Thus the characters and the live audience get involved in the therapy gradually unfolding before them in what Aristotle calls catharsis. 


\section{Chris Egharevba}

However, a group therapy is not so much an individual identification with the emotional strength or weakness of the character(s) as with the nature of the drama itself. A theatrical performance that focuses on issues of the daily experiences of the masses- their joys and pains, their hopes and deferred hopes, disappointment, and indeed their daily struggle to find solution to life's drama and elicits positive response from both performers and audience is the hallmark of group therapy.

A therapy suggests the presence of an illness, a sickness that requires gradual treatment. Group therapy implies that such solution requires more than individual. And in this discussion, the group consists of the audience and performers with the playwright as the therapist whose main task is to guide the group to self-discovery.

The main benefit of group therapy is that people behave and react more like themselves in a group setting than they would individually. Audience may have different emotional traits and values in the context of a group and faced by theatre performers before them. There is a harnessing, a submerging of emotions, a surrendering to the issues raised by the drama. Group therapy is a form of psychotherapy in which several patients discuss their personal problems with the main aim of raising the patients' awareness and morale and foster uninhibited self- revelation. It is a method of psychological healing.

Drama therapy is the use of theatre techniques to facilitate personal growth and promote health. In other words, it is the modern use of dramatic process and theatre as a therapeutic intervention to solving a problem, achieving a catharsis or delving into truths about self. Drama Therapy according Denys Kyriacov "has many ancient, historical roots in the healing rituals and dramas of various societies" it forms the meeting point of psychology and drama, and stresses on the ability of drama to heal and recognize human awareness. (On line)

A therapeutic theatre is a functional theatre, it goes beyond mere aesthetics. It highlights socio-political and economic problem of society but more than this, it proffers solution to these problems. Thus dramatherapy offers the possibility of change through increased insight and self-awareness and by providing the opportunity to experiment with different ways of thinking, feeling and behaving. Chris Nwamuo's theatre pioneer's the essence of group therapy and dramatherapy.

\section{III}

The Prisoners is a play with the socialist paradigms of the masses-willoverthrow-the system model. The play presents the experience of four solders - Obi, Onwu, Buchi and Mezie who by running away from the warfront had become war prisoners. The prison officials who are supposed to take care of the war prisoners fed fat on the consignment of food supply meant for the prisoners. Unable to bear the hunger, the prisoners, led by Obi, revolt. In a hastily planned mutiny, they steal food from the stores and eventually dispossess the prison officials. 
The play dramatizes the extent to which human patients can be stretched as seen in the experience of the prisoners. In the face of hunger and the desire for survival, the young men took their destinies into their hands and collectively determine to confront their oppressors. This collective action culminates in a change of their lives. Thus, although the solders ran from the war front, in the home front, they fought two wars. First, they fought against hunger; second, they fought for freedom.

And as the playwright suggests, our major war is the war at the home front; the fight against, poverty, hunger, deprivation and the fight for freedom, against oppression and bondage. These the solders tackled as the Superintendent of Prisons concluded in the play. (lifting up his head and indicating some pain in his waist) we are all prisoners of one system or the other, struggling for freedom from our oppressors. (The music while you work continues as he is forced down to continue the grass-cutting. Later Obi orders Onwu to March them out of the scene as he, Mezie and Buchi stand at attention and stare into the future. Light fade). (Emphasis mine) (The squeeze and other plays, p.132).

What does the future hold for the oppressed, the down trodden, the prisoners of the system? The answer to this question takes the play beyond pedagogy to a collective therapy for the masses to escape the prison of poverty and dehumanization.

The Prisoners is a drama that has its root in pedagogy theatre, However, in Nwamuo's theatre The Prisoners belongs to a stage of transition from essentially pedagogic drama to drama therapy. His theatre now develops beyond, the masses-will-overthrow to a profound examination of the peoples problem to arrive at a therapy for better awareness of self, the truth and reality of situation that only a group therapy can unfold.

Child abuse, lack of parental concern for the future is the concern of Nwamuo in The Last Song. In fact, "any action" the playwright emphasizes taken by a custodian of a younger person, which borders on psychological violence, unnecessary exposure to danger, inadequate medical care, neglect, assault and injustice; or any maltreatment meted out to a young person, because he is ill-equipped to fight back or because he is in a disadvantage position, amount to child abuse. ( 3 plays, p68)

The play The Last Song" explores the psychological and social doubt of the Nigerian child and calls on parents teachers, guardians, the legal system, the family support programme and government, to condemn any acts of child abuse, as a way of protecting the rights of the child" (p.68).

Parents need to realize that in spite of the differences between them after a child is born, the moment of making the child was a beautifully and enjoyable moment and that a child does not decide to be born into the world. It is the responsibility of both parents to care for their product. The old man narrator provides the admonition; Narrator: For bringing forth children into the world, Parents should make their children the centre of their affection (3 plays, p. 20) 


\section{Chris Egharevba}

But a broken relationship and broken home generate hatred that engulfs the child. The last song is a drama therapy that is directed towards people that have combined to bring another human being into the world, that they should understand the essence of care, of nurturing and of responsibility.

According to Nwamuo in his prefatory note to Save Our Lives, "one of the major preoccupations of theatre is to recreate, re-order and heighten significant incidents and experiences in order to draw attention, for remediation" (3 plays, p.41) Remediation becomes possible after a therapeutic process which the drama provides.

Nwamuo observes that theatre practitioners all over the world have come a long way from discussing the philosophy, aims and purpose of the theatre. What they are concerned with today, are how to map out appropriate techniques, strategies, methods and approaches for making theatre stronger and more virile than it is currently, and how best to make theatre themes more relevant to target audiences in order to bring about change in their lives" ( 3 plays $\mathrm{p} .41)$.

Here comes the essence of group therapy. Chris Nwamuo's theatre is "a theatre that identifies with the issues that concern the mass of the people, a theatre that identifies with issues with a view to shock people and proffer remediation steps." (41). and here lies the focus of drama therapy.

According to the playwright, The wisdom of the king was originally conceived as a mass literacy campaign package to remind the adult population's inclination to the wanton destruction of the eco-system, of the need to conserve nature. It is aimed at drawing our attention to the ecocidal tendency due to our ignorance of preserving nature. It is therefore a therapeutic piece to cure the audience and generate awareness of preserving the ecosystem in all forms.

As the characters present the issues at stake in the drama and gradually come to a realization of the issues raised, the audience is engineered towards a therapeutic solution.

In The wisdom of the King, Nwamuo, the dramatherapist takes us to the world of nature by highlighting our ecophobic and ecocidal tendency. The issue is one that the audience needs a therapeutic solution. This is very significant is this age of environmental awareness. The basic truth is that we have to be conscious of the damages or harm we are inflicting on the environment and the earlier we are made aware of the danger to human existence by our neglect of the environment, the better. Hence we need the treatment of drama therapy to jolt us from our ignorance.

The play opens with the king presenting a frivolous reason for his decision to destroy the environment. The Umutu Community where the play is set has always been in harmony with the forest around it but now the king's son had been called a "bush man" by his classmate. And so the king decides that the forest must go (3 plays p.26).

The playwright proceeds to enlighten the king about the dangers of his ecophobic decisions. He indicates that nature provides a soothing balm for a 


\section{A Study of Chris Nwamuo's Theatre}

restless humanity. But man because of his ecocidal tendencies finds it difficult to utilize this panacea for longevity. Man cannot benefit from nature fully when his relationship with the environment is filled with destruction and exploitation. It is only a healthy relationship that can give birth to fulfillment. Man had to realize the dangers to himself in his ecocidal stance with the environment. This is the focus of this drama therapy about man and the environment a play that should heal our ignorance about the world around us.

The Squeeze is a domestic drama where marriage is negatively affected by poverty and adultery. It develops to examine what constitute the measure of a man. The play shows that man in debased by the lack of the means of livelihood. Man's sense of identity and responsibility are eroded by poverty occasioned by unemployment. Okoro is an unemployed graduate of civil engineering married with a pregnant wife but lacks the ability of providing for his wife and the unborn child. He faces humiliating insults and harassment from his landlord and his mistress. The Okoro in Act1 sene1 is a picture of poverty who had suffered real hardship not because he was not educated but because he lacks an effective "background" need in society that is materialistically structured.

An illiterate like the Chief had the required "background". He moves about with thugs, manhandles Okoro and nothing happened to him. The chief is not a stranger to the system. He possesses the true identity to live a life of comfort. When we come to Act 2. we meet, Okoro who "is haggard-looking and roughly dressed" who had taken severe beating by life generally. $\mathrm{He}$ "behaves like a mentally deranged man" and walks like one possessed" The squeeze, pp 38-39).

His appearance and behaviour elicits fear in his younger brother Emeka. But it is the product of penury. Okoro is so stressed that his perception of things emanates from this frustration. He became jealous of his brother who he sees as being favoured by life. He confronts his brother to paint a picture that embodies his concept of life. The existential problems he faced provide empirical documentation about the meaninglessness of life, "Squeezed" or "peppered" by life that his existence bordered on insanity. Okoro tells the story of those who society has abandoned.

Okoro: (Angry) This is my story you know. I am telling it my own way. Don't you forget that. imprint... that's my image. You get an imprint from a design you known. (The squeeze, p. 49).

He tells the story from his own perspective, the story of those frustrated by life and those driven to insanity.

But Emeka's privilege position makes him to reject involvement in his brother's situation Okoro: Life has no answer to fires of the mind. Emeka: (Jumping out of his seat) well, I am not going to be involved in your painting and your woman. (The squeeze, p.53) Emeka's declining involvement 


\section{Chris Egharevba}

portends danger. The confrontation between Okoro and Emeka drives home the dangerous denouement between the favoured and the frustrated. Frustration, anger, lack of recognition and egotism drive Okoro to murder his younger brother. This is a drama therapy per-excellence. The tragic end of the Uloho's family underscores the tragic existence of those without financial identity in a nation that is cursed with irresponsible leaders. It is a profound statement about the bleakness of the future of such a society that have no regard for the quality of the life of its citizens.

The Substitute is one of Nwamuo's best examples of dramatherapy. It is a play that examines the issue of loneliness that engulfs one in the event of the loss of a loved one. How does one cope with loneliness in the face of the death of a spouse? What is the best remedy for a lonely soul? The Substitutes takes a look at the emotional problems of loneliness and suggests companionship as the appropriate therapy for loneliness.

The play begins by portraying a state of despair and loneliness in the very loaded expression "There is indeed a spell hanging over the silence" emphasizing the intensity of emotional loneliness engulfing Ngozi the widow. The playwright proceeds to present two people in similar situations or circumstances but with different responses. Mr Jatau the landlord of the late Mr Adebayo, Ngozi's husband, had also lost his lovely wife. But he had overcome the sorrow and pain of the loss and come to a personal realization that life must go on. He decides to face life with optimism. This he had to pass on to Ngozi by accepting the role of a substitute. To carry on in life after the loss of a spouse there is the need for a substitute. The Substitute is a beautifully crafted therapeutic drama. It is a play that succinctly portrays relationship as the therapy for loneliness. It is a play that shows that finding love again after love is the elixir for life.

\section{CONCLUSION}

Chris Nwamuo's theatre is not an elitist theatre. It is a theatre that treats issues of the masses - their hopes, their fears, their aspirations, their problems, their daily struggles and response to life, in fact, Nwamuo's theatre focuses on the daily realities of the masses. His theatre is not a theatre that alienates but attracts the masses as they face what in essence is the realities of their existence. Be it the problem of disease like Guinea worm in Save Our Lives, or the problem of excruciating poverty occasion by unemployment or refreshment as in The Squeeze or the ecocidal problem of the village of Umuhu as in The wisdom of the king Nwamuo's theatre is geared towards therapeutic solution of issues raised in the drama. Hence Nwamuo's theatre is a therapeutic theatre.

Drama therapy dynamically and effectively addresses the needs of the people and is rooted in the belief in the healing power of drama. We need healing, physical and emotional healing. The society needs healing, our environment needs healing. Our nation needs healing "a nation that pays 


\section{A Study of Chris Nwamuo's Theatre}

premium to politics to the detriment of education" needs healing. A nation that pays lip service to the truth, to fundamental issues of development and toys with its future, needs healing. When we have a society where leaders dethrone integrity from their character and mortgage the future of their youths and the entire citizenry, we need more dramatherapist like Chris Nwamuo to let the society face the truth about itself.

\section{WORKS CITED}

Egharevba, Chris. "The Wisdom of the King: a Study in Ecodrama" Sankofa vol 2, No 2, Accra.June, 2004. 82-97.

Idoye, Patrick. "Theatre and Conscientization. The African Example." In Theatre and Drama in National Development (ed.) Chris, Nwamuo, Calabar. 1986. 71-83

Nwamuo Chris, The Sqeeze and other Plays. Kraft books Lagos. 1992

- 3 Plays. AP Publications, Owerri. 1996

. "Soyinka and the Philosophy of Nigerian Theatre" in Calabar Journal of Liberal Studies vol v No II Dec,2002. 1-17

--. Essentials of Theatre Administration. University of Calabar Press, Calabar, 2003

--. The Prisoners. Tana Press, Enugu. 2003.

- Theatre Audience Engineering in Nigeria: Paradigm and Syntagm. University of Calabar $32^{\text {nd }}$ Inaugural Lecture, University Press. Calabar, March, 2006. 